\title{
A Study of the Prophylactic and Curative Effect of Melatonin on Postoperative Delirium after Coronary Artery Bypass Grafting Surgery in Elderly Patients
}

\author{
Samia I. Sharaf, Dalia A. Nasr El-Din, Mostafa G. Mahran, Dalia F. Ali Nawar, \\ Dalia I. El-Naggar \\ Department of Anesthesia and Intensive care, Faculty of Medicine, Ain Shams University \\ Corresponding author: Dalia Ibrahim Mohamed El-Naggar; Mobile: 01006215850; Email: daliaibrahim555@gmail.com
}

\begin{abstract}
Background: delirium is a common complication after cardiac surgical procedures and is associated with increased morbidity and mortality. Postoperative delirium is associated with an increased length of stay in the intensive care unit, long hospital stay and high hospital charges. Aim of the Work: to investigate the effectiveness of melatonin as a preoperative sedative as well as the preventive and the curative effect of melatonin supplementation in elderly patients undergoing coronary artery bypass surgery on postoperative delirium. Patients and Methods: this prospective, randomized, controlled, double blind study was conducted on a total of 50 patients allocated into 2 equal groups. It was conducted in Ain Shams University hospitals, in the cardiothoracic surgery unit. Results: melatonin has superior sedative effect at $30 \mathrm{~min}$ preoperatively compared with placebo $(\mathrm{P}=0.022)$. Melatonin succeeded to treat about $56 \%$ of delirious patients. The incidence of delirium was $8 \%$ in the melatonin group vs. $28 \%$ in the control group $(\mathrm{P}=0.046)$. In univariate analysis, predictors of delirium in both groups were age $(\mathrm{P}=0.049$ in melatonin group, $\mathrm{P}=0.021$ in control group), higher fentanyl dose $(\mathrm{P}=0.021$ in melatonin group, $\mathrm{P}=0.047$ in control group $)$, lower ejection fraction $(\mathrm{P}=0.018$ in melatonin group, $\mathrm{P}=0.008$ in control group), longer cardiopulmonary bypass $(\mathrm{CPB})$ times $(\mathrm{P}=0.026$ in melatonin group, $\mathrm{P}=0.04$ in control group) and longer aortic cross clamping ( $\mathrm{ACC}$ ) times $(\mathrm{P}=0.04$ in melatonin group, $\mathrm{P}=0.019$ in control group). Conclusion: administration of melatonin significantly decreased the incidence of postoperative delirium (POD) after coronary artery bypass grafting in elderly patients and significantly increased preoperative sedation. Advanced age, higher total intraoperative fentanyl dose, lower ejection fraction and longer $\mathrm{CPB}$ and ACC times were independent predictors of POD with or without melatonin supplementation.
\end{abstract}

Keywords: melatonin, postoperative delirium, coronary artery bypass grafting, elderly

\section{INTRODUCTION}

Delirium is an acute or subacute organic mental syndrome characterized by disturbance of consciousness, global cognitive impairment, disorientation, the development of perceptual disturbance, attention deficits, decreased or increased psychomotor activity, disordered sleepwake cycle, and fluctuation in presentation. The term "delirium", from the Latin roots de (meaning "away from") and lira (meaning "furrow in a field") and ium (Latin for singular), literally means "a going off the ploughed track, a madness", (1).

Delirium is a common complication in elderly patients after cardiac surgery and is associated with adverse outcomes including prolonged hospital stay and increased mortality ${ }^{(2)}$.

The incidence of postoperative delirium ranges from 10 to $46 \%$ in general surgical population and reaches 50 to $67 \%$ among the patients undergoing cardiac surgery ${ }^{(3)}$.

Drugs have been associated with the development of delirium in the elderly. Successful treatment of delirium depends on identifying the reversible contributing factors, and drugs are the most common reversible cause of delirium.
Anticholinergic medications, benzodiazepines, and narcotics in high doses are common causes of drug induced delirium ${ }^{(4)}$.

Melatonin by virtue of its multiple functions has the potential to take a place in the anesthetic drug armamentarium, because it can be an attractive option for premedication as an anxiolytic and sedative, for the induction of general anesthesia as a hypnotic or as an induction adjuvant and perioperatively for analgesia. Melatonin can also be used postoperatively to store sleep rhythm and prevent delirium ${ }^{(5)}$.

\section{AIM OF THE WORK}

The aim of this work is to investigate the effectiveness of melatonin as a preoperative sedative as well as the preventive and the curative effect of melatonin supplementation in elderly patients undergoing coronary artery bypass surgery on postoperative delirium.

\section{PATIENTS AND METHODS}

\section{Study design and sampling}

After approval of the Research Ethics Committee and written informed patient consent, 
this prospective, randomized, controlled, double blind study was conducted on 50 patients allocated into 2 equal groups. This study was conducted at Ain Shams University hospitals, in the Cardiothoracic Surgery unit.

Inclusion criteria Elective coronary artery bypass grafting surgery. Two or three vessel grafts. Age $\geq 60$ years, both sexes. ASA physical status III-IV.

Exclusion criteria: Emergent coronary artery bypass grafting surgery. ASA physical status $\geq V$. Ejection fraction $<40 \%$. Patients with preoperative Mini Mental State Examination (MMSE) score $\leq 24$. History of neuropsychiatric disorders. History of liver cirrhosis or renal failure. History of chronic pulmonary diseases. Uncontrolled systemic disease e.g. uncontrolled diabetes mellitus or systemic hypertension. Serious perioperative or postoperative complications causing unexpected morbidity e.g. sepsis, thromboembolic events, etc. Prolonged postoperative ventilation $>8$ hours. History of chronic sedative hypnotics use $>3$ times/week during a month prior to cardiac surgery. Allergy to the study drugs or one of their ingredients.

Randomization: Patients who met all the inclusion criteria were randomized to either Group M (Melatonin group) or Group C (Control group) by using computer generated random numbers with closed sealed envelope.

Endpoint: Non occurrence of delirium during the first three postoperative days. The need for further evaluation and treatment of postoperative delirium among delirious patients who did not respond to melatonin.

\section{Methods}

All patients were fasted according to standard rules and were seen and examined by an anesthesiologist at the night of the surgery.

All patients were screened at that time by MiniMental state examination (MMSE) according to Folstein ${ }^{(6)}$ test. The maximum score is 30 . Patients with MMSE score $\leq 24$ were excluded from the study.

Group M (Melatonin group): received 3 mg melatonin orally at 9 p.m. the night before surgery and another $3 \mathrm{mg}$ melatonin with $15 \mathrm{ml}$ of plain water $30 \mathrm{~min}$ before operation and $3 \mathrm{mg}$ melatonin at 9 p.m. in the day of operation after weaning from mechanical ventilation and the first three postoperative days.
Group C (Control group): received a placebo that looked the same and packaged the same way as melatonin at the same times.

The anesthesia residents who administered the drug the night before the surgery and the ICU residents who administered the study drugs and assessed Intensive Care Delirium Screening Checklist (ICDSC) postoperatively were all blinded to the allocation regimen.

On arrival to the preanesthesia room at 9 a.m., sedation was assessed by a five - point clinical global impression (CGI) sedation score for all the patients. The maximum sedation score is 4 and the minimum score is 0 .

All patients received their routine cardiac medication until day of surgery. IV antibiotic was started. All Patients were monitored with five lead ECG, invasive arterial blood pressure after radial artery catheterization, oxygen saturation, capnography and a nasopharyngeal temperature probe.

Induction of anesthesia was done with fentanyl $(10 \mu \mathrm{g} / \mathrm{kg})$, thiopental $(3-4 \mathrm{mg} / \mathrm{kg})$, midazolam $(0.03-$ $0.05 \mathrm{mg} / \mathrm{kg}$ ) and rocuronium $(0.6 \mathrm{mg} / \mathrm{kg})$.

Intubation was done with oral cuffed endotracheal tube size 7-7.5 mm ID for females and 7.5-8 $\mathrm{mm}$ ID for males.

Right internal jugular central venous catheter was placed after induction for all patients.

Anesthesia was maintained with isoflurane (0.75- $1 \%)$, incremental doses of rocuronium every 30 minutes and increments of fentanyl up to a total dose of $20 \mu \mathrm{g} / \mathrm{kg}$.

After surgery, patients were transferred to ICU mechanically ventilated, planned for weaning from mechanical ventilation as soon as they reach hemodynamic stability, consciousness and adequate pain control.

Patients of Group $M$ received $3 \mathrm{mg}$ melatonin at 9 p.m. in the same operative day after weaning from mechanical ventilation and the following three postoperative days.

Intensive Care Delirium Screening Checklist (ICDSC) was reported in the same day after operation (Day-0) and in the followed three postoperative days (Day-1, Day-2 and Day-3). All patients were vitally stable and normothermic at the time of evaluation. Patients who had ICDSC score $\geq 4$ were considered to have postoperative delirium ${ }^{(7)}$. These patients 
received $3 \mathrm{mg}$ melatonin orally at 9 p.m. daily and ICDSC was reassessed daily for up to 3 successive days after delirium development. A psychiatrist was consulted for further management if there was no response to melatonin.

Measured variables: Preoperative variables: hemoglobin level, serum creatinine, BUN, SGOT, SGPT, albumin, ejection fraction and Mini-mental state (MMSE) score. Preoperative sedation score. Total doses of intraoperative narcotics (pre, post and during cardiopulmonary bypass). End tidal concentration of inhalational anesthetics. Number of grafts. Aortic cross clamping time and cardiopulmonary bypass time. Time for weaning from mechanical ventilation. Postoperative delirium: The postoperative delirium was assessed by implementing the Intensive Care Delirium Screening Checklist (ICDSC). Including altered level of consciousness, the ICDSC consists of eight items (rated present or absent), and each patient was given a score from 0 to $8 ; 4$ or greater is considered diagnostic of delirium ${ }^{(7)}$.

\section{Statistical analysis}

Using Power Analysis and Sample Size (PASS) 13, group sample size of 25 patients per group achieved $80 \%$ power to detect a difference of $15 \%$ in the reduction of delirium incidence between the two groups with a significant alpha level of 0.05 .

Data were analyzed using Statistical Package for Social Science (SPSS) version 21.0. Chicago, Illinois, USA. Quantitative data were expressed as mean \pm standard deviation. Qualitative data were expressed as number of patients and percentage. The independent-samples t-test was used to compare between means in the two groups. Skewed numerical data are presented as median (range) and independent samplesmedian test was used to compare between medians in both groups. Chi square test was used to compare proportions between two qualitative parameters. Univariate analysis was used to test the predictors of delirium. $P$-value $<0.05$ was considered significant and $P$-value $<0.01$ was considered highly significant.

\section{RESULTS}

\section{Demographic data}

Group $\mathrm{M}$ and Group C were comparable regarding age, sex weight, American Society of Anesthesiologists Physical Status (ASA-PS) and past medical history, no statistically significant differences between both groups were found ( $\mathrm{P}$ value >0.05) (table 1).

Table (1): Demographic data.

\begin{tabular}{|l|c|c|c|}
\hline \multicolumn{1}{|c|}{ Variable } & $\begin{array}{c}\text { Group } \\
\text { M(n=25) }\end{array}$ & $\begin{array}{c}\text { Group } \\
\text { C(n=25) }\end{array}$ & P-value \\
\hline Age (years) & $66.56 \pm 4.79$ & $67.88 \pm 4.13$ & 0.303 \\
\hline Weight (Kg) & $84.61 \pm 10.41$ & $83.88 \pm 11.12$ & 0.814 \\
\hline Sex (M/F) & $12 / 13$ & $14 / 11$ & 0.571 \\
\hline ASA-PS (III/IV) & $14 / 11$ & $13 / 12$ & 0.777 \\
\hline $\begin{array}{l}\text { Medical history } \\
\text { (None/DM/HTN/Both }\end{array}$ & $5 / 6 / 7 / 7$ & $3 / 7 / 8 / 7$ & 0.886 \\
\hline
\end{tabular}

Data presented as mean $\pm \mathrm{SD}$ or number of patients; $\mathrm{P}$-value $>0.05$ is considered statistically non-significant;

ASA-PS=American Society of Anesthesiologists Physical status; DM=Diabetes mellitus and HTN=Hypertension.

\section{Preoperative variables}

The preoperative variables (Hemoglobin "Hb" level, serum creatinine, BUN, SGOT, SGPT, albumin, ejection fraction "EF" and Mini-Mental State Examination "MMSE" score) showed no significant difference between the two groups ( $\mathrm{P}$ value> 0.05) (table 2).

Table (2): Preoperaive variables.

\begin{tabular}{|l|c|c|c|}
\hline \multicolumn{1}{|c|}{ Variable } & $\begin{array}{c}\text { Group } \\
\text { M(n=25) }\end{array}$ & $\begin{array}{c}\text { Group } \\
\text { C(n=25) }\end{array}$ & P-value \\
\hline $\mathrm{Hb}(\mathrm{gm} / \mathrm{dl})$ & $12.66 \pm 1.20$ & $12.48 \pm 1.17$ & 0.595 \\
\hline Creatinine $(\mathrm{mg} / \mathrm{dl})$ & $1.01 \pm 0.24$ & $0.82 \pm 0.17$ & 0.06 \\
\hline BUN $(\mathrm{mg} / \mathrm{dl})$ & $18.28 \pm 4.19$ & $18.84 \pm 4.65$ & 0.657 \\
\hline SGOT $(\mathrm{mg} / \mathrm{dl})$ & $40.28 \pm 5.30$ & $38.52 \pm 5.29$ & 0.246 \\
\hline SGPT $(\mathrm{mg} / \mathrm{dl})$ & $41.60 \pm 6.53$ & $44.28 \pm 7.24$ & 0.176 \\
\hline Albumin $(\mathrm{gm} / \mathrm{dl})$ & $4.12 \pm 0.41$ & $5.78 \pm 8.38$ & 0.330 \\
\hline EF $(\%)$ & $58.40 \pm 6.37$ & $59.08 \pm 6.43$ & 0.709 \\
\hline MMSE & $29(27-30)$ & $29(28-30)$ & 0.773 \\
\hline
\end{tabular}

Data presented as mean \pm SD or median (range); P-value > 0.05 is considered statistically non-significant

$\mathrm{BUN}=\mathrm{Blood}$ urea nitrogen; $\mathrm{EF}=$ Ejection fraction; $\mathrm{Hb}=\mathrm{Hemoglobin}$; MMSE=Mini-Mental State Examination; SGOT=Serum glutamic oxaloacetic transaminase and SGPT=Serum glutamic pyruvic transaminase.

\section{Intraoperative and postoperative variables}

Isoflurane end-tidal concentration (\%), total doses of fentanyl consumed $(\mu \mathrm{g})$, aortic cross clamping time $(\mathrm{min})$ and bypass time $(\mathrm{min})$ were all recorded intra-operatively (table 3 ). 
Table (3): Intraoperative and postoperative variables.

\begin{tabular}{|l|c|c|c|}
\hline \multicolumn{1}{|c|}{ Variable } & $\begin{array}{c}\text { Group M } \\
(\mathbf{n = 2 5})\end{array}$ & $\begin{array}{c}\text { Group C } \\
(\mathbf{n = 2 5})\end{array}$ & P-value \\
\hline $\begin{array}{l}\text { Isoflurane end tidal } \\
\text { concentration }(\%)\end{array}$ & $1 \pm 0.176$ & $1.1 \pm 0.16$ & 0.936 \\
\hline $\begin{array}{l}\text { Fentanyl consumed } \\
(\mu \mathrm{g})\end{array}$ & $1250 \pm 156.79$ & $1234 \pm 140.47$ & 0.706 \\
\hline CPB (min) & $66.52 \pm 17.42$ & $68.4 \pm 23.17$ & 0.747 \\
\hline ACC time (min) & $44.4 \pm 13.01$ & $41.6 \pm 11.06$ & 0.416 \\
\hline Number of grafts & $2(2-3)$ & $3(2-3)$ & 0.777 \\
\hline $\begin{array}{l}\text { Time for weaning } \\
\text { from ventilator } \\
\text { (hours) }\end{array}$ & $5.76 \pm 1.48$ & $5.60 \pm 1.08$ & 0.664 \\
\hline
\end{tabular}

Data presented as mean \pm SD or median (range); P-value $>0.05$ is considered statistically non-significant

$\mathrm{ACC}=$ Aortic cross clamping and $\mathrm{CPB}=$ Cardiopulmonary bypass .

\section{Assessment of sedation}

Sedation was assessed by a five point scale at 30 min after the premedication in the morning of the surgery. The results demonstrated that melatonin was associated with higher sedation compared to placebo $(\mathrm{P}$-value $=0.002)($ table 4$)$.

Table (4): Sedation score.

\begin{tabular}{|c|c|c|c|}
\hline Score & $\begin{array}{c}\text { Group } \\
\mathbf{M}(\mathbf{n}=\mathbf{2 5})\end{array}$ & $\begin{array}{c}\text { Group } \\
\mathbf{C}(\mathbf{n}=\mathbf{2 5})\end{array}$ & \multirow{2}{*}{ P-value } \\
\hline 0 & 19 & 25 & \multirow{2}{*}{0.022} \\
\hline 1 & 6 & 0 & \multirow{2}{*}{0.0} \\
\hline 2 & 0 & 0 & \\
\hline 3 & 0 & 0 & \\
\hline 4 & 0 & 0 & \\
\hline
\end{tabular}

Data presented as number of patients; P-value $<0.05$ is considered statistically significant

\section{Assessment of postoperative delirium (POD)}

POD was assessed by using Intensive Care Delirium Screening Checklist (ICDSC) on postoperative days $0,1,2$ and 3 . The cutoff ICDSC score to diagnose delirium was $\geq 4$. The results demonstrated that there was a significant decrease in the incidence of delirium among the patients who received prophylactic melatonin (Group $\mathrm{M}$ ) compared to Group C (P-value < 0.05).The use of prophylactic melatonin had succeeded to decrease the incidence of POD from 28\% to 8\% (table 5).

Table (5): Delirium data in both groups.

\begin{tabular}{|c|c|c|c|}
\hline Delirium data & $\begin{array}{c}\text { Group M } \\
(\mathbf{n}=\mathbf{2 5})\end{array}$ & $\begin{array}{c}\text { Group C } \\
(\mathbf{n}=\mathbf{2 5})\end{array}$ & P-value \\
\hline Incidence of delirium & $2(8 \%)$ & $7(28 \%)$ & \\
\hline $\begin{array}{l}\text { Number of patients who } \\
\text { developed delirium on: } \\
\text { Day-0 }\end{array}$ & 1 & 5 & \\
\hline Day-1 & 1 & 1 & 0.046 \\
\hline Day-2 & 0 & 1 & \\
\hline Day-3 & 0 & 0 & \\
\hline
\end{tabular}

Data is presented as number of patients or $(\%)$; P-value $<0.05$ is considered statistically significant

\section{Melatonin as a therapeutic agent in patients who developed delirium in both groups}

Assessment of delirium by ICDSC was further extended to another three days in patients who developed ICDSC score $\geq 4$ in either group on Day- $0,1,2$ or 3 .

All patients in Group M who developed delirium on the same day of surgery or any of the first three postoperative days were cured in response to melatonin therapy "ICDSC score dropped below 4" (table 6).

Three (3) out of seven (7) patients who developed delirium in Group C on the same day of surgery or any of the first three postoperative days were cured in response to melatonin therapy "ICDSC score dropped below 4" (table 6).

Two (2) out of seven (7) patients who developed delirium in Group $\mathrm{C}$ on the same day of surgery or any of the first three postoperative days improved but were not cured in response to melatonin therapy "ICDSC score still $=4$ " (table 6).

Two (2) out of seven (7) patients who developed delirium in Group C on the same day of surgery or any of the first three postoperative days did not respond to melatonin therapy (table 6).

Table (6): Response to melatonin therapy in patients who developed delirium in both groups.

\begin{tabular}{|l|c|c|c|}
\hline & $\begin{array}{c}\text { Group M } \\
(\mathbf{n = 2 5})\end{array}$ & $\begin{array}{c}\text { Group C } \\
(\mathbf{n = 2 5 )}\end{array}$ & P-value \\
\hline Incidence of delirium & $2(8 \%)$ & $7(28 \%)$ & \\
\cline { 1 - 3 } $\begin{array}{l}\text { Number of patients who were } \\
\text { cured after melatonin therapy }\end{array}$ & $2(100 \%)$ & $3(42.9 \%)$ & \\
\cline { 1 - 3 } $\begin{array}{l}\text { Number of patients whose } \\
\text { ICDSC score improved but }\end{array}$ & 0 & $2(28.6 \%)$ & \multirow{2}{*}{0.046} \\
$\begin{array}{l}\text { were not cured in response } \\
\text { to melatonin therapy }\end{array}$ & 0 & $2(28.6 \%)$ & \\
$\begin{array}{l}\text { Number of patients who did } \\
\text { not respond to melatonin } \\
\text { therapy }\end{array}$ & 0 & \\
\hline
\end{tabular}

Data is presented as count or (\%); P-value $<0.05$ is considered statistically significant

ICDSC=Intensive Care Delirium Screening Checklist

\section{Univariate analysis of variables in both groups in association with delirium}

Univariate analysis of the variables of both groups confirmed that older age $\geq 70$ years ( $\mathrm{P}$ value $=0.049)$, longer $\mathrm{CPB}$ time $\geq 60 \mathrm{~min}(\mathrm{P}$-value $=0.026)$, longer $\mathrm{ACC}$ time $\geq 45 \mathrm{~min}(\mathrm{P}$-value $=$ $0.04)$, lower $\mathrm{EF}<55 \%(\mathrm{P}$ value $=0.018)$ and higher fentanyl dose $>1200 \mu \mathrm{g}(\mathrm{P}$-value $=0.021)$ were independently associated with POD (table7). 
Table (7): Univariate analysis of the different independent variables in relation to the incidence of delirium in Group M.

\begin{tabular}{|c|c|c|c|c|c|c|}
\hline \multirow{2}{*}{ Category } & \multirow{2}{*}{ Number } & \multirow{2}{*}{$\begin{array}{l}\text { Number with } \\
\text { delirium }(\%)\end{array}$} & \multirow{2}{*}{ P-value } & \multirow{2}{*}{ OR } & \multicolumn{2}{|c|}{$95 \%$ CI } \\
\hline & & & & & Lower & Upper \\
\hline Age $\geq 70$ years & 9 & $2(22.2 \%)$ & 0.049 & 2.286 & 1.124 & 4.198 \\
\hline Male gender & 12 & $0(0 \%)$ & 0.175 & -- & -- & -- \\
\hline DM and /or HTN & 20 & $2(10 \%)$ & 0.157 & $\overline{--}$ & $\overline{--}$ & $\overline{--}$ \\
\hline $\mathrm{EF}<55 \%$ & 7 & $2(28.6 \%)$ & 0.018 & 3.61 & 1.19 & 6.834 \\
\hline $\begin{array}{l}\text { Fentanyl dose } \geq \\
1200 \mu \mathrm{g}\end{array}$ & 20 & $1(5 \%)$ & 0.021 & 1.211 & 1.011 & 4.121 \\
\hline ACC time $\geq 45 \mathrm{~min}$ & 14 & $1(7.1 \%)$ & 0.04 & 1.769 & 1.043 & 13.866 \\
\hline CPB time $\geq 60 \mathrm{~min}$ & 16 & $2(12.5 \%)$ & 0.026 & 1.643 & 1.036 & 11.631 \\
\hline
\end{tabular}

Data is presented as number of patients or $(\%)$; P-value $<0.05$ is considered statistically significant

ACC $=$ Aortic cross clamping; $\quad \mathrm{CBP}=$ Cardiopulmonary bypass; $\mathrm{CI}=$ Confidence interval; $\mathrm{DM}=$ Diabetes Mellitus; $\mathrm{EF}=$ Ejection fraction; $\mathrm{HTN}=$ Hypertension and $\mathrm{OR}=$ Odds ratio.

Table (8): Univariate analysis of the different independent variables in relation to the incidence of delirium in Group C.

\begin{tabular}{|c|c|c|c|c|c|c|}
\hline \multirow{2}{*}{ Category } & \multirow{2}{*}{ Number } & \multirow{2}{*}{$\begin{array}{l}\text { Number with } \\
\text { delirium }(\%)\end{array}$} & \multirow{2}{*}{$\begin{array}{c}P- \\
\text { value }\end{array}$} & \multirow{2}{*}{ OR } & \multicolumn{2}{|c|}{$95 \%$ CI } \\
\hline & & & & & Lower & Upper \\
\hline $\begin{array}{l}\text { Age } \geq 70 \\
\text { years }\end{array}$ & 9 & $5(55.6 \%)$ & 0.021 & 8.75 & 1.124 & 4.198 \\
\hline Male gender & 14 & $5(35.7 \%)$ & 0.332 & -- & -- & -- \\
\hline $\begin{array}{l}\text { DM and /or } \\
\text { HTN }\end{array}$ & 22 & $6(27.3 \%)$ & 0.683 & -- & -- & -- \\
\hline $\mathrm{EF}<55 \%$ & 8 & $5(62.5 \%)$ & 0.008 & 12.5 & 1.6 & 97.647 \\
\hline $\begin{array}{l}\text { Fentanyl dose } \\
\geq 1200 \mu \mathrm{g} \\
\end{array}$ & 19 & $6(31.6 \%)$ & 0.047 & 2.308 & 1.219 & 24.316 \\
\hline $\begin{array}{l}\text { ACC time } \geq \\
45 \mathrm{~min}\end{array}$ & 12 & $6(50 \%)$ & 0.019 & 12.124 & 1.164 & 13.68 \\
\hline $\begin{array}{l}\text { CPB time } \geq \\
60 \mathrm{~min}\end{array}$ & 15 & $6(40 \%)$ & 0.002 & 6.025 & 1.596 & 60.437 \\
\hline
\end{tabular}

Data is presented as number of patients or $(\%)$; P-value $<0.05$ is considered statistically significant

ACC $=$ Aortic cross clamping; $\quad \mathrm{CBP}=$ Cardiopulmonary bypass; $\mathrm{CI}=$ Confidence interval; $\mathrm{DM}=$ Diabetes Mellitus; $\mathrm{EF}=$ Ejection fraction; $\mathrm{HTN}=$ Hypertension and $\mathrm{OR}=\mathrm{Odds}$ ratio.

\section{DISCUSSION}

Delirium after cardiac surgery is a major problem. The exact mechanisms behind delirium are not fully understood. Several predisposing and precipitating risk factors have been identified for delirium. The development of delirium following cardiac surgery is associated with worse outcomes in the perioperative period. Multiple interventions are being explored for the prevention and treatment of delirium. Studies investigating the potential pharmacological interventions to reduce the incidence of delirium are necessary to mitigate this negative outcome ${ }^{(8)}$.

There is growing interest in the perioperative use of melatonin for its potential analgesic, sedative and anxiolytic effects. In the current work, the perioperative use of melatonin was discussed for its potential prophylactic and therapeutic role in delirium in elderly patients.

The results of the present study showed that melatonin succeeded as a prophylaxis against POD in elderly patients undergoing CABG. It reduced the incidence of POD from $28 \%$ to $8 \%$. Also melatonin was used as a therapy in patients who developed POD and was successful to treat about $56 \%$ of cases. Premedication with melatonin also proved a sedative effect. The correct dosage of melatonin in humans seems largely unknown ${ }^{(9)}$.

Pharmacokinetic studies of orally administered melatonin (3 $\mathrm{mg}$ ) in critically ill patients showed serum peak after 16 minutes and therapeutic levels were maintained up to 10 hours following administration ${ }^{(\mathbf{1 0})}$.

A possible clinical effect and an appealing safety profile makes melatonin an interesting new drug for the perioperative setting. Moreover, widely used analgesics, anxiolytics and sedatives are associated with risk of side effects such as respiratory depression, Postoperative delirium (POD) and postoperative nausea and vomiting (PONV). The use of melatonin might decrease the risk of serious complications in the perioperative period ${ }^{(9)}$.

The sedative of melatonin was investigated in the current study. The results demonstrated higher sedation score at $30 \mathrm{~min}$ after premedication with melatonin compared to placebo.

These results were consistent with those published by Pokharel $\boldsymbol{e t}$ al. ${ }^{(11)}$ who compared the effects of oral melatonin (3 mg), alprazolam (0.5), a combination of both medications and placebo on preoperative sedation and anxiety. Regarding sedation, they found that the three groups including melatonin (3 $\mathrm{mg}$ ) are significantly sedated at $30 \mathrm{~min}$ and $60 \mathrm{~min}$ after premedication. These results matched those of Sultan ${ }^{(12)}$ who found significant sedation with melatonin (5 $\mathrm{mg}$ ) at $30 \mathrm{~min}$ after premedication compared to the control group in patients undergoing hip arthroplasty under spinal anesthesia.

In the current study, Melatonin succeeded to decrease the incidence of POD from $28 \%$ to $8 \%$. The overall incidence of POD in both groups was $18 \%$.

Artemiou et al. (13) had studied the prophylactic role of melatonin in the prevention of POD after cardiac surgery. They had found that the incidence of POD among cardiac surgery patients is $14.6 \%$ in both groups with delirium developed in $20.8 \%$ in control group vs. $8.4 \%$ in melatonin 
group. This may indicate the effectiveness of the melatonin dose $(3 \mathrm{mg})$ used in the current study in the prevention of POD as it showed comparable results with the higher dose of $5 \mathrm{mg}$.

Burkhart et al. ${ }^{(14)}$ studied the modifiable and non-modifiable risk factors for POD after elective cardiac surgery with cardiopulmonary bypass (CPB) in patients aged 65 or older and reported the incidence of POD in these patients as $30 \%$.

On the other hand, Smulter et al. ${ }^{(15)}$ diagnosed delirium in $54.9 \%$ in their study upon 142 elderly patients aged 70 or more scheduled for routine cardiac surgery. They targeted older population in their study group.

The incidence of POD reaches up to 50$67 \%$ among the patients undergoing cardiac surgery. Wide variations in reported incidence depend on methodological differences between the studies, mainly concerning the implementation of delirium diagnostic tools and the characteristics of the study populations ${ }^{(3)}$.

So, different assessment tools for POD as Confusion Assessment Method for the Intensive Care Unit (CAM-ICU) and Mini Mental State Examination (MMSE) could be another explanation of higher incidence of POD.

The original validation study of CAM-ICU demonstrated a sensitivity between $95 \%$ and $100 \%$ and aspecificity between $89 \%$ and $93 \%$. The validation of ICDSC was performed in a medicalsurgical ICU, yielding a sensitivity of $99 \%$ and a specificity of $64 \%$. When comparing these 2 tools, there are some advantages and disadvantages from each method. In general, the CAM-ICU does not depend exclusively on the verbal response, thus being relevant for patients on mechanical ventilation ${ }^{(16)}$. ICDSC was implemented in the current study as delirium assessment was conducted in the study groups only after extubation.

It is worth noting that all above mentioned studies which aimed at investigating POD in cardiac surgery did not focus on a homogenous operative group in contrast to the present study which was limited to patients undergoing CABG.

Regarding the heterogeneous cardiac surgery populations targeted in different studies, there may be a different factor in every type of cardiac surgery which may play a predominant role in the development of POD. For example aortic manipulation and atherosclerotic microembolization during cannulation and cross-clamping in CABG, whereas air bubbles trapped in the cardiac chambers may play a significant role in the development of delirium in valve surgery ${ }^{(\mathbf{1 7})}$.In this context, Artemiou et al. ${ }^{(13)}$ found that CABG and CABG combined with valve surgeries were all confirmed to be associated with an increased risk for the development of POD than the valve surgery alone. However, Hudetz et al. ${ }^{(18)}$ had reported more frequent $\mathrm{POD}$ in patients undergoing valve surgery with or without $\mathrm{CABG}$ compared with $\mathrm{CABG}$ alone. This may also attribute to the vast differences in the reported incidence of POD after cardiac surgery and contributes to the multifactorial etiology of delirium.

The efficacy of melatonin in POD was shown in many studies upon patient populations other than cardiac surgery patients. Al-Aama et al. ${ }^{(\mathbf{1 9})}$ had found that a low dose of melatonin $(0.5 \mathrm{mg})$ decreased the incidence of delirium in elderly patients aged 65 and over admitted through the emergency department to a medical unit (12\% vs. $31 \%$ ).

Also, Sultan ${ }^{(12)}$ found in his study upon elderly patients scheduled for hip arthroplasty under spinal anesthesia that perioperative melatonin decreased POD to $9.43 \%$ compared to $32.56 \%$ in the control group.

Melatonin was used in the current study for treatment of POD in a total of nine (9) patients; two (2) patients in Group M and seven (7) patients in Group C. The success rate of melatonin to treat POD was about $56 \%$. Another two (2) patients in Group $\mathrm{C}$ had improved ICDSC score in response to melatonin but they were not fully cured (ICSDC score improved but did not go down below 4). So melatonin succeeded to let ICDSC score go down (with or without total cure) in about $78 \%$ of all patients who developed delirium.

These results were comparable to those of Sultan ${ }^{(12)}$ who studied the role of melatonin as a therapy in patients who developed POD after hip arthroplasty under spinal anesthesia. In his study, melatonin effectively treated thirty six (36) patients out of a total of sixty two (62) patients who developed delirium in the same day of surgery or any of the first three postoperative days in any of his study groups (the success rate was about $58 \%$ ).

The results of the current study showed no statistically significant difference in the total doses of fentanyl consumed intraoperatively in the melatonin group compared to placebo. 
In agreement with these results, Artemiou $\boldsymbol{e t}$ $a l .{ }^{(13)}$ found no statistically significant difference in the total doses of sufentanil $(P$-value $=0.286)$ or benzodiazepines $(P$-value $=0.116)$ in the melatonin group when compared to the control group.

Also Naguib and Samarkandi (20) evaluated the perioperative effects of melatonin premedication $(5 \mathrm{mg})$ compared to midazolam and placebo in women undergoing laparoscopic gynecological surgeries. There was no significant difference in the intraoperative opioid use or total doses of analgesics consumed in the melatonin, midazolam or placebo groups.

In contrast, Caumo et al. ${ }^{(21)}$ who studied the narcotic sparing effect of melatonin upon patients undergoing abdominal hysterectomy found that melatonin $(5 \mathrm{mg})$ resulted in reduction of postoperative morphine consumption by $30 \%$ compared to the control group in their study.

Also Ionescu et al. ${ }^{(22)}$ studied melatonin as a premedication in patients undergoing laparoscopic cholecystectomy. The patients received melatonin (3 $\mathrm{mg}$ ) the night before the surgery and in the morning as a premedication. They found that melatonin lowered the intraoperative fentanyl requirements in comparison to placebo.

A possible explanation for the conflicting results regarding the narcotic sparing effect of melatonin is the enrollment of dissimilar operative groups in different studies, employment of different melatonin doses, adopting different anesthetic techniques and vast differences in operative times especially when comparing cardiac surgery to general surgery.

In the current study, no statistically significant difference in isoflurane end tidal concentration was found between melatonin and placebo. No studies had investigated the influence of melatonin on the requirements of inhalational anesthetics.

In the present study, univariate analysis of various predictors of POD in both Group $\mathrm{M}$ and Group C showed statistical significance of older age as an independent variable of POD development. This matched the results of Kazmierski et al. ${ }^{(23)}$ who revealed that advanced age was independently associated with delirium after cardiac surgery in their study. Artemiou et al. (13) also found that older age was a predictor of POD in patients undergoing cardiac surgery.
Furthermore, different intraoperative predictors were found in the present study to be associated with POD. The higher the fentanyl dose $(\geq 1200 \mu \mathrm{g})$, the higher was the risk for developing POD. This correlated with the results of the study done by Artemiou et al. ${ }^{(13)}$ who found the same correlation for higher sufentanil doses $\geq 15 \mu \mathrm{g}$ in the control group in patients undergoing cardiac surgery. Also there was a significant association between longer cardiopulmonary bypass (CPB) times $\geq 60 \mathrm{~min}$ and aortic cross clamping (ACC) times $\geq 45$ min with delirium. Going with similar results, Andrejaitiene and Sirvinskas ${ }^{(24)}$ reported that ACC times more than $68 \mathrm{~min}$ is associated with the development of POD. Artemiou et al. ${ }^{(13)}$ also reported this association in the control group.

Interestingly, Artemiou et al. ${ }^{(13)}$ found that administration of melatonin eliminated the association of the predictors linked to time with delirium (total sufentantil dose, ACC time and CPB time). In other words, they found that the perioperative predictors of POD in the melatonin group were limited to advanced age and higher EuroScore II. This may be due to usage of higher melatonin dose $(5 \mathrm{mg})$ or inclusion of wider age group with different types of cardiac surgery in their study.

\section{CONCLUSION}

Premedication with melatonin in the current study significantly increases preoperative sedation. Moreover, the administration of melatonin significantly decreases POD in elderly patients undergoing $\mathrm{CABG}$ in the current study. Melatonin also has been proved successful as a therapeutic agent in delirious patients. Univariate analysis for risk factors of delirium indicated that advanced age, higher total intraoperative fentanyl dose, lower ejection fraction and longer CPB and ACC times were independent predictors of POD with or without melatonin supplementation.

\section{REFERENCES}

1. Maldonado JR (2008): Pathoetiological model of delirium: A comprehensive understanding of the neurobiology of delirium and an evidencebased approach to prevention and treatment. Critical Care Clinics, 24(4):789-856.

2. Bakker RC, Osse RJ, Tulen JH et al. (2012): Preoperative and operative predictors of delirium after cardiac surgery in elderly patients. European Journal of Cardiothoracic Surgery, 41:544-549. 
3. Norkienė I, Ringaitienė D, Kuzminskaitė V et al. (2013): Incidence and risk factors of early delirium after cardiac surgery. BioMed Research International, 2013:323491.

4. Alagiakrishnan K and Wiens CA (2004): An approach to drug induced delirium in the elderly. Postgraduate Medical Journal, 80:388-393.

5. Kurdi MS and Patel T (2013): The role of melatonin in anesthesia and intensive care. Indian Journal of Anesthesia, 57(2):137-144.

6. Folstein MF, Folstein SE and McHugh PR (1975): Mini Mental state- A practical method for grading the cognitive state of patients for the clinician. Journal of Psychiatric Research, 12(3): 189-198.

7. Bergeron N, Dubois MJ, Dumont $\mathrm{M}$ et al. (2001): Intensive care delirium screening checklist: Evaluation of a new screening tool. Intensive Care Medicine, 27(5):859-864.

8. O'Neal JB and Shaw AD. (2016): Predicting, preventing, and identifying delirium after cardiac surgery. Perioperative Medicine, 5:7.

9. Andersen LPH, Rosenberg $J$ and Gogenur I (2014): Perioperative melatonin: not ready for prime time. British Journal of Anesthesia, 112(1):7-8.

10. Mistraletti G, Sabbatini GandTaverna $M$ et al. (2010): Pharmacokinetics of orally administered melatonin in critically ill patients. Journal of Pineal Research, 48(2):142-147.

11. Pokharel $K$, Tripathi $M$, Gupta PK et al. (2014): Premedication with oral alprazolam and melatonin combination: A comparison with either alone - A randomized controlled factorial trial. Biomed Research International. https:// www.hindawi.com/journals/bmri/2014/356964/

12. Sultan SS (2010): Assessment of role of perioperative melatonin in prevention and treatment of postoperative delirium after hip arthroplasty under spinal anesthesia in the elderly. Saudi Journal of Anesthesia, 4:169-173.

13. Artemiou P, Bily B, Bilecova-Rabajdova $M$ et al. (2015): Melatonin treatment in the prevention of postoperative delirium in cardiac surgery patients. Polish Journal of Cardiothoracic Surgery, 12(2):126-133.

14. Burkhart CS, Dell-Kuster S, Gamberini $M$ et al. (2010): Modifiable and non-modifiable risk factors for postoperative delirium after cardiac surgery with cardiopulmonary bypass. Journal of Cardiothoracic and Vascular Anesthesia, 24(4):555-559.
15. Smulter N, Lingehall HC, Gustafson Y et al. (2013): Delirium after cardiac surgery: Incidence and risk factors. Interactive Cardiovascular and Thoracic Surgery, 17:790-798.

16. Tomasi CD, Grandi C, Salluh J et al. (2012): Comparison of CAM-ICU and ICDSC for the detection of delirium in critically ill patients focusing on relevant clinical outcomes. Journal of Critical Care, 27(2):212-217.

17. Sabol F, Bily $B$ and Artemiou $P$ (2015): Incidence and risk factors of delirium in patients after cardiac surgery: Modifiable and nonmodifiable factors. Coret Vasa, 57(3): 168-175.

18. Hudetz JA, Iqbal Z, Gandhi SD et al. (2011): Postoperative delirium and short-term cognitive dysfunction occur more frequently in patients undergoing valve surgery with or without coronary artery bypass graft surgery compared with coronary artery bypass graft surgery alone: results of a pilot study. Journal of Cardiothoracic and Vascular Anesthesia, 25(5):811-816.

19. Al-Aama T, Brymer $\mathrm{C}$, Gutmanis $I$ et al. (2011): Melatonin decreases delirium in elderly patients: A randomized, placebocontrolled trial. International Journal of Geriatric Psychiatry, 26:687-694.

20. Naguib $M$ and Samarkandi AH (1999): Premedication with melatonin: A double-blind, placebo-controlled comparison with midazolam. British Journal of Anesthesia, 82:875-880.

21. Caumo W, Levandovski $R$ and Hidalgo MP (2009): Preoperative anxiolytic effect of melatonin and clonidine on postoperative pain and morphine consumption in patients undergoing abdominal hysterectomy: A double-blind, randomized, placebo-controlled study. The Journal of Pain, 10(1):100-108.

22. Ionescu D, Bãdescu C, Ilie A et al. (2008): Melatonin as premedication for laparoscopic cholecystectomy: A double-blind, placebocontrolled study. South Africa Journal of Anesthesia and Analgesia, 14(4): 08-11.

23. Kazmierski J, Kowman M, Banach $M$ et al. (2010): Incidence and predictors of delirium after cardiac surgery: Results from The IPDACS Study. Journal of Psychosomatic research, 69(2):179-185.

24. Andrejaitiene $J$ and Sirvinskas E (2011): Early post-cardiac surgery delirium risk factors. Perfusion, 27(2):105-112. 